\title{
Combining accessibilities for different activity types: Methodology and case study
}

\author{
Lijuan Zheng \\ Institute of Urban and Transport Planning \\ RWTH Aachen University \\ lijuan.zheng@outlook.com
}

\section{Bert van Wee}

Delft University of Technology

G.P.vanWee@tudelft.nl

\author{
Markus Oeser \\ RWTH Aachen University \\ oeser@isac.rwth-aachen.de
}

Abstract: Accessibility is a key concept in transport planning. Most studies only focus on specific activity types, but for policy making it is more relevant to aggregate accessibility overall or at least several activity types. However, to the best of our knowledge, there is no study that combines accessibilities for different activity types. Since access to spatially separated activities is one dimension of quality of life, and activity types are not equally important for quality of life, we propose a methodology that is based on weighing activity types according to their relative importance to quality of life to assess overall accessibility. Four principles are adopted to develop the weighting factors: 1) the human needs the activity types satisfy; 2) the activity types' contribution to quality of life; 3) the activity types' trip frequency; 4) further modifications, based on principles such as whether the activity types are needed in emergent situations, and social values and policy preferences. We combine these four principles and apply the methodology in a case study focused on Germany.

\section{Article history:}

Received: February 2, 2019

Received in revised form:

September 10, 2019

Accepted: October 7, 2019

Available online: December 3,

2019

\section{Introduction}

Accessibility usually means the ability of people to access spatially distributed activities, or the ability of activity-facilities to attract people (Curl, Nelson, \& Anable, 2011; Rubulotta, Ignaccolo, Inturri, \& Rofe, 2013). It addresses the main function of the transport system, which is to enable people and businesses to access location-dependent activities, e.g., working, shopping, leisure (Halden, 2002). Conventional transport planning is based on the analysis of mobility-based indicators, e.g., trip frequency, travel time and travel distances (in general or by mode). The focus of transport planning is mainly on improving the efficiency of the transport system by adding new connections or increasing the capacity of existing connections to cope with increased demand and - in the case of the road system - to reduce congestion. It is not always the case that improving the transport system efficiency contributes to improving accessibility. For example, increasing the capacity of the road system may contribute to urban sprawl and consequently reduce the levels of accessibility, at least for some people and activity types. Consequently, several authors have emphasized that transport planning should pay more attention to accessibility-based analyses (El-geneidy \& Levinson, 2006; Litman, 2017).

Copyright 2019 Lijuan Zheng, Bert van Wee, \& Markus Oeser

http://dx.doi.org/10.5198/jtlu.2019.1529

ISSN: $1938-7849$ | Licensed under the Creative Commons Attribution - Noncommercial License 4.0

The Journal of Transport and Land Use is the official journal of the World Society for Transport and Land Use (WSTLUR) and is published and sponsored by the University of Minnesota Center for Transportation Studies. 
Accessibility measures quantify accessibility levels and play an essential role in making the concept of accessibility applicable in practice. Accessibility measures usually include two basic elements: the attractiveness of the activity or activity location and the travel resistance to reach the activity. The resistance can be expressed in terms of time, distance, or Generalized Transport Costs (GTC). The role GTC plays in the value of an accessibility indicator is specific to the activity type and is often expressed as a so-called impedance function, often based on real world travel behavior data. For example, people accept longer travel times to work than to go grocery-shopping. As a result, the impedance function differs between these activity types, and it would be more accurate if accessibility was quantified for each activity type (Geurs \& Ritsema van Eck, 2001).

In papers on accessibility analysis the researchers often only select some specific activity types to analyze (Foth, Manaugh, \& El-Geneidy, 2013; Grengs, 2015; Halden, 2002; Karou \& Hull, 2014; Reyes, Páez, \& Morency, 2014), work being the most commonly studied (Grengs, 2015). Other activity types / locations studied include: shopping (Elldér, 2014; Great Britain Social Exclusion Unit, 2003; Grengs, 2015; Lucas, Bates, Moore, \& Carrasco, 2016), healthcare facilities (Elldér, 2014; Great Britain Social Exclusion Unit, 2003; Grengs, 2015; Wachs \& Kumagai, 1973), educational facilities (Grengs, 2015), leisure facilities (Elldér, 2014; Great Britain Social Exclusion Unit, 2003; Grengs, 2015; Karou \& Hull, 2014), city centers (Department for Transport, 2005; Karou \& Hull, 2014), and parks (Reyes et al., 2014). The studies vary in the level of detail to which these activity types are categorized. For example, Grengs (2015) analyzed the accessibility of restaurants and social visits while other papers analyzed leisure activities in general (Elldér, 2014; Great Britain Social Exclusion Unit, 2003; Karou \& Hull, 2014). The UK Department for Transport (2005) analyzed access to different types of educational facilities (primary school, secondary school and further education) (Department for Transport, 2005), while in Grengs (2015) "going to school" is an activity type which is not further disaggregated.

While there can be good reasons for assessing accessibility levels for specific activity types, for transport policy-making overall accessibility (involving all activity types) is more relevant. We found one study that included all activity types, Dalvi and Martin (1976), clustering all activity types into two categories, work and other. Analyzing accessibility at a more detailed level provides more accuracy. For policy makers, however, overall accessibility is more relevant, and communicating the accessibility implications of policy options at an aggregate level to policy makers and other clients of accessibility research is easier.

To the best of our knowledge there is no empirical study that involves combining accessibilities for different activity types at a more disaggregated level than the study of Dalvi and Martin (1976). Only one paper (Church \& Marston, 2003) proposes a method to combine accessibility for different activity types theoretically but does not apply it in practice. The proposed method weighs the accessibilities by the corresponding activity type's trip frequency and sums the weighted accessibilities.

Being able to access spatially distributed activities is regarded as one dimension of quality of life (Karou \& Hull, 2014). As activity types are not equally important for life (Campbell, Converse, \& Rodgers, 1976), we suggest that the individual contribution of different activity types to quality of life is useful in order to aggregate accessibility for different activity types. Weighing different types of accessibility in one way or another is inevitable to achieve this aim.

Trip frequency alone is not sufficient to represent the relative importance, because it is affected by external constraints, including an individual's ability to conduct the activity type (e.g., income, education level), transport characteristics (e.g., travel cost and public transport station distribution), and landuse characteristics (e.g., density, mixture of land use) (Yen \& Adamowicz, 1994). Personal ability involves financial ability, psychological and physiological ability. For example, people with higher incomes might have higher ability to conduct activity types that require relatively high travel costs. For example, Zhan, Yan, Zhu, and Wang (2016) found that family income affects students' trip frequency. The characteristics of the transport system also matter. The proximity of transit stations influences students' travel 
frequency (Zhan et al., 2016), for example, and pedestrian-oriented design reduces motorized trip frequency significantly (Cervero \& Kockelman, 1997). We therefore argue that the methods to assess the accessibility of all activity types at an aggregate level should be based on more than trip frequency alone. Such a method does not exist yet.

The purpose of this study therefore is to develop a method involving a number of principles to assess the relative importance of activity types to quality of life (see Section 2), based on existing data and research, to get a set of weighting factors to combine the accessibilities of different activity types. The relative contribution to quality of life of each activity type is used to develop the weighting factors, as will be explained in Section 2. The added value of the paper is not in deriving weighting factors, but in showing how, based on available datasets, quality of life can be used as a guiding principle to aggregate accessibility over multiple trip purposes. The structure of this paper is as follows: in Section 2, the theories to weigh accessibilities over different activity types are presented; the steps to generate weighting factors, underpinned by the theories presented in Section 2 and its application to a real-world case in Germany are presented in Section 3; Section 4 discusses the method.

\section{Theories to weigh accessibilities over different activity types}

This section aims to combine a number of theoretically underpinned principles to assess the relative importance of activity types to quality of life, which are then used to weigh accessibilities over a set of different activity types. The theories are presented to underpin the principles theoretically, rather than to give a comprehensive and overarching literature review of all the relevant theories.

First, we will briefly present the principles to develop weighting factors. Next, we will theoretically underpin the first principle that it can be relevant to distinguish between categories of human needs, and why we prefer to distinguish two categories, fundamental human needs and supplemental human needs. These categories are then used to categorize related activity types. Next, we will present a conceptual model for the contribution of accessibility, via activities, to quality of life, which explains why the second principle (see below) can be used to generate weighting factors to combine the accessibilities of different activity types. Finally, we will show how, based on available datasets, we obtain the quantitative data of activity type's "relative contribution to quality of life."

\subsection{Summary of principles to weigh accessibilities over activity types}

We adopt four principles to set the weights for different activity types to generate aggregated accessibility (see Figure 1).

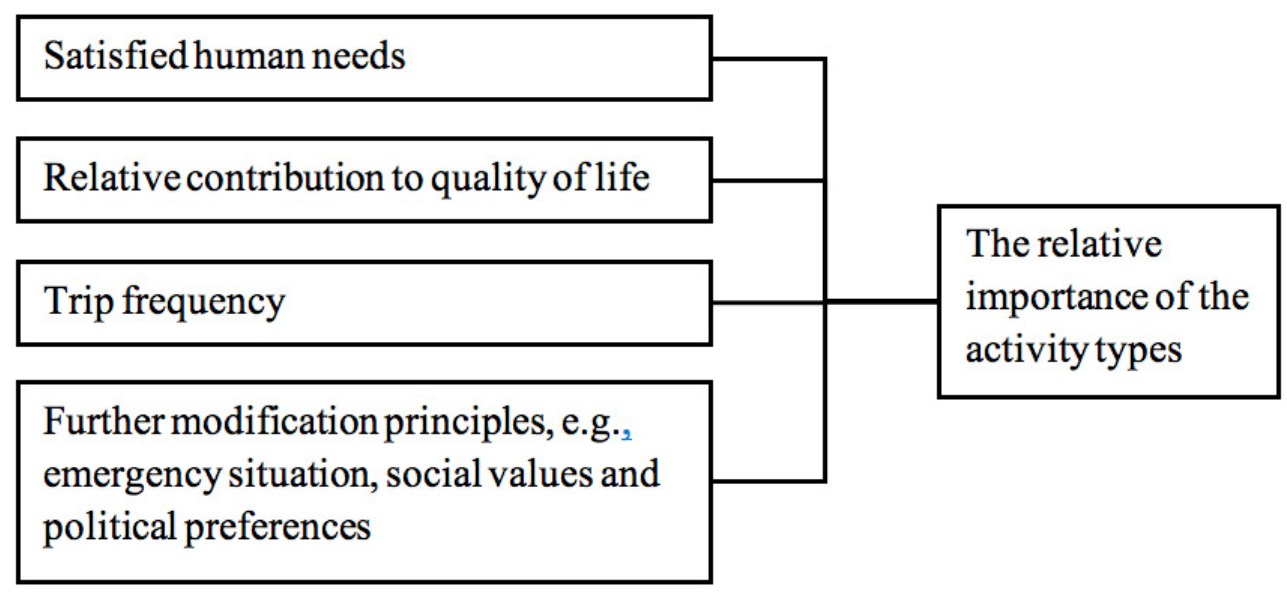

Figure 1. The principles to set the weights to generate the aggregated accessibility 
The first principle is to categorize activity types according to human needs categories: activities to satisfy fundamental needs (e.g., the need for food, clothing, etc.) and activities to satisfy supplemental needs (e.g., the need for leisure time). As displayed in Section 2.1, the reason why people conduct activities is to satisfy their human needs. We argue that a healthy society should ensure or try to ensure that all people can satisfy their fundamental human needs, which are needed to survive. Correspondingly, the accessibility to these activity types should be ensured. Similarly, van Wee and Geurs (2011) also argued that, inspired by the work of philosopher Rawls (1971), it is "defendable to argue that a basic level of access to some destinations could be labelled as a "primary social good." This principle makes accessibility research more suitable for social exclusion analyses.

Next, for each activity category we assess the relative importance of the activity types using the other three principles.

The second principle is to weigh activity types according to their relative contribution to quality of life, which is represented by the relative contribution to quality of life of the corresponding life domains. Being able to access spatially distributed activities is regarded as one dimension of quality of life (Karou \& Hull, 2014; Pyrialakou, Gkritza \& Fricker, 2016). The contribution to quality of life of different life domains, which might involve one or more activity types, varies (Andrews \& Withey, 1974; Campbell et al., 1976; Cummins, Eckersley, Pallant, van Vugt, \& Misajon, 2003; Saxena, Carlson, Billington, \& Orley, 2001; The World Health Organization Quality of Life Group, 1998). This is discussed in more detail in Subsection 3.3. Our proposal is to weigh activity types based on quantitative assessments of the life domains' contribution to quality of life.

Linking the first two principles it is important to notice that there is disagreement on whether satisfying supplemental human needs contributes more to quality of life than satisfying fundamental human needs. According to Maslow's hierarchy of needs theory, satisfying supplemental needs contributes more to quality of life (Maslow, 1970). But Betz (1984) argued that satisfying higher level human needs does not necessarily always contribute more to life satisfaction. According to the empirical study result by Campbell et al. (1976), some supplemental needs contribute more to life satisfaction than basic needs, but not all. For example, work satisfies a basic need; friendship satisfies a higher-level need; the former makes a greater contribution to life satisfaction than the latter.

The third principle is weighing activity types according to another quantitative indicator: trip frequency. Some life domains involve more than one activity type. A principle is therefore needed to further weigh activity types within a life domain. We propose using trip frequency for this purpose. Note that trip frequency is not only based on the needs of people but is also subject to constraints that restrict activity participation. Hence, it is an indicator of the relative importance of activity types in daily life, but not a perfect one.

The fourth principle aims to further modify the weighting factors according to other principles, such as whether or not an emergency situation exists, and social values and political preferences. Emergency situations can be very important, and even make the difference between life and death, for example requiring urgent medical care or escaping an erupting volcano. Consequently, we argue that, for example, access to a hospital should be weighed higher than average. One could argue that the occurrence of emergency situations can be interpreted as a specific case of fundamental needs, but because of its specific nature we propose to explicitly address this as part of the fourth principle. Also, social values and political preference can play a role in weighing. In Germany, the government propose a slogan "shorter legs shorter trips," which means that trip length should be shorter for younger people, e.g., the trip length to primary schools/kindergartens. Considering this policy preference, the accessibility to primary schools and kindergartens should be weighed higher. 


\subsection{Human needs for categorizing activity types}

Our argument for classifying human needs into two categories (fundamental needs and supplemental needs) will now be presented. These two categories can then be used to categorize activity types.

A number of human needs systems have been proposed. One well-known system is Maslow's hierarchy of needs. According to Maslow (1970), human beings have five hierarchies of needs that motivate people to conduct activities. From low level to high level, these needs are: physiological needs, safety needs, love and belonging needs, esteem needs, and self-actualization needs. There is overlap between the different need-hierarchies in Maslow's needs theory (Alderfer, 1969): safety needs involve security of the environment as well as protection from others, where the former overlaps with physiological needs, and the latter with love and belonging needs; esteem needs involve respect/esteem from others as well as self-respect, where the former part is similar to love and belonging needs, and the latter is similar to self-actualization needs.

Regarding these overlaps, Alderfer (1969) proposed a new human needs system which he labels "ERG theory." "E" refers to existence needs, "R" refers to relatedness needs, "G" refers to growth needs. The correlation between the human needs category in ERG theory and Maslow's needs theory is showed in Table 1.

Jones (1983) developed a more simplified framework of human needs (as cited in Fox, 1995), utilizing two need groups. The first group is fundamental needs, which includes subsistence needs (e.g., food, shelter, clothing, health care) and the activities which provide income to meet these needs. These needs are mainly related to surviving. The second group is supplemental needs (the culturally, socially and individually defined needs), which are satisfied by engaging in a variety of social and recreational activities.

Table 1. Links between the need categories of Maslow and ERG theory

\begin{tabular}{|c|c|c|c|c|}
\hline Human need system & \multicolumn{2}{|c|}{ Maslow's hierarchy of needs } & ERG theory of needs & $\begin{array}{l}\text { Rough categories of } \\
\text { needs }\end{array}$ \\
\hline \multirow[t]{7}{*}{ Human needs category } & \multicolumn{2}{|c|}{ physiological needs } & \multirow[t]{2}{*}{ existence needs } & \multirow[t]{2}{*}{ fundamental needs } \\
\hline & \multirow[t]{2}{*}{ safety needs } & physical threat & & \\
\hline & & interpersonal & \multirow[t]{3}{*}{ relatedness needs } & \multirow[t]{5}{*}{ supplemental needs } \\
\hline & \multicolumn{2}{|c|}{ Love $\&$ belonging needs } & & \\
\hline & \multirow[t]{2}{*}{ esteem needs } & Interpersonal & & \\
\hline & & Self & \multirow[t]{2}{*}{ growth needs } & \\
\hline & \multicolumn{2}{|c|}{ self-actualization needs } & & \\
\hline
\end{tabular}

Because there are overlaps between the need hierarchies in Maslow's theory, it does not provide an ideal model to categorize related activities. In addition, both Maslow's need hierarchy and ERG theory are developed to describe adults' needs. They are not necessarily applicable for children's needs. Besides, some activities can satisfy multiple need categories. In modern societies, most people still do not surpass level 3 and level 4 of Maslow's need categories (Ventegodt, Merrick, \& Andersen, 2003). They are still struggling to satisfy the love and belongingness need and the esteem need. The level 5, the self-actualization need, is rarely satisfied (Ventegodt et al., 2003). It is not necessary to distinguish the higher-level needs in detail. Based on this discussion of needs we propose that a rough categorization of needs into two categories, fundamental needs and supplemental needs, is the preferred model to categorize related activities for our purposes. 


\subsection{Conceptual model of human activity pattern}

Next, we will present how activity-conduction contributes to quality of life, which explains why activity types' relative contribution to quality of life can be used to generate weighting factors.

We depart from the conceptual model as presented in Figure 2. According to this model, people conduct activities in order to satisfy their human needs. Vice versa, conducting activities contributes to satisfying human needs. Satisfying human needs contributes to improving quality of life, which "as a general term is meant to represent either how well human needs are met or the extent to which individuals or groups perceive the satisfaction or dissatisfaction in various life domains " "Costanza et al., 2007, p. 268). So, conducting activities influences quality of life because these human needs are being satisfied by these activities. A major, probably overarching, goal for both policy makers and individuals is to improve quality of life (Costanza et al., 2007). There are a variety of constraints that prevent people from conducting activities, such as financial restrictions, low level of accessibility, or time constraints. Policies that reduce these constraints can improve conditions for conducting activities. Examples include income policies, improving the transport system and land-use policies. Note that also external factors can influence constraints, but for reasons of simplicity these are not conceptualized in Figure 2. For example, autonomous vehicles could reduce driving constraints for visually impaired persons.

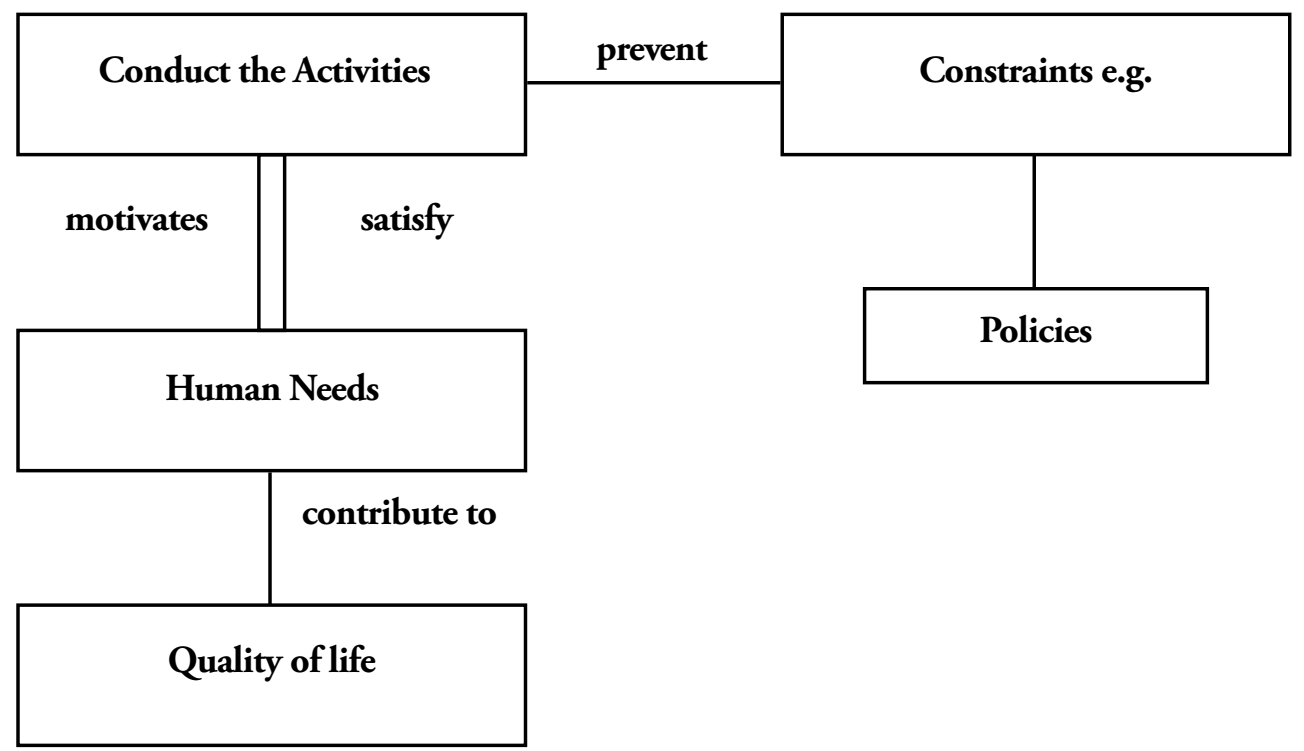

Figure 2. A conceptual model for the impact of conducting activities on quality of life

In our conceptual model, there are two assumptions:

- Individuals are motivated by their human needs to conduct activities. And vice versa: conducting activities contributes to human needs being satisfied.

- The ability to conduct an activity depends on the constraints of the individuals and/or the environments, such as the financial ability to conduct the activities, and the spatial distribution of the activity-facilities.

A number of theories support these two assumptions. The first theory is the so-called motivational theory: individuals strive to achieve a state of stability. When they realize that there is an insufficient

\footnotetext{
${ }^{1}$ Life domains refer to different aspects of life, such as health, community, financial situation, housing conditions. Some life domains involve one or more out-door activity types, while others not.
} 
level of satisfaction of needs, the stability is disrupted, and they tend to conduct activities to satisfy their human needs (Fodness, 1994; Goossens, 2000). The greater the insufficiency, the greater the tendency to fix it (Mc Fadden, 1974). In other words, human activities are derived from the demand to satisfy human needs, such as material and physiological needs, and the need for interpersonal connection. And conducting activities therefore contributes to satisfying human needs.

The second theory is developed by Chapin (1968), which illustrates how motivation/ human needs is converted to human activity. According to this theory, individuals are first motivated to conduct activities to satisfy human needs. Next, they make the decision on whether and how to conduct the activity, influenced by the constraints posed on them by personal characteristics (e.g., the financial ability) and by the environment (e.g., the spatial distribution of the destinations).

The third theory that supports our assumptions is the push-pull theory (Goossens, 2000). "Push" factors refer to the motivations that push people to conduct the activity; "pull" factors refer to the characteristics of the destinations that attract people to conduct the activity. Goossens (2000) proposed that only if there is a product or service (with proper quality, acceptable cost, etc.) that individuals expect to have "a positive effect on satisfying that now conscious needs" (Goossens, 2000), will individuals be motivated to buy the product or access the service.

These theories have been applied to analyze daily life activity patterns. Fox (1995) proposed that "activity choice" is a process of satisfying needs, subject to constraints. Chapin (1968) argued that people's activity pattern in daily life is prompted by inner human needs, and activity pattern is influenced by, and vice versa influences, land use.

Up to now we have underpinned the assumptions that activity conduction is motivated by human needs and constrained by the options available to satisfy these needs. We will now turn our attention to the assumption that satisfying human needs contributes to improving quality of life. We can underpin this claim easily by referring to the definition of quality of life. According to Costanza et al. (2007), quality of life represents how well human needs are met. Maslow also proposed that a good life is about satisfying human needs (Ventegodt et al., 2003).

Since activity-conduction is to satisfy human needs, and satisfying human needs contributes to improving quality of life, it is easy to conclude that conducting activities contributes to quality of life. This is underpinned by several publications. For example, Ettema, Gärling, Olsson, and Friman (2010) argued that engaging in various daily activities influences quality of life because activities help to satisfy human needs, such as self-achievement. In addition, there are a number of empirical studies that test the relationship between activity-conduction and quality of life. The results show that activities contribute to quality of life. For example, Bergstad et al. (2012) asked respondents in a questionnaire to assign a value to the affect associated with each of nine most frequently undertaken out-of-home activities according to the nationwide Swedish travel survey, and to assess people's mood and life satisfaction (in this context: a synonym for quality of life). ${ }^{2}$ They then estimated a multiple linear regression model to test the influence of each activity's effect on mood and on life satisfaction. The results reveal that affection towards activities influences life satisfaction and mood, and thus influences quality of life.

As shown in Figure 2, policies can influence activity participation by reducing constraints, and thus improve quality of life. A low level of accessibility is one constraint that prevents people from conducting activities. Accessibility can be improved in two ways: 1) provide more activity facilities so that the distance to facilities is shorter; 2) improve transport service level so that people can overcome the spatial separation more easily. Policies can be developed from these two aspects to improve accessibility and thus reduce the constraints for activity participation.

\footnotetext{
${ }^{2}$ In this paper, the concept of life satisfaction refers to the extent to which individuals perceive satisfaction with the different life domains or life as a whole. Quality of Life represents "the extent to which individuals or groups perceive the satisfaction or dissatisfaction in various life domains" (Costanza et al., 2007, p. 268). So, in this paper life satisfaction is a synonym for quality of life.
} 


\subsection{Weighing activity types based on a life domain's contribution to quality of life}

The extent to which different life domains (e.g., health, community, religious faith, etc.) contribute variously to quality of life (Andrews \& Withey, 1974; Campbell et al., 1976; Frisch, 1998), has been quantitatively analyzed in a number of studies.

There are a number of methods to assess the relative importance of life domains. The most straightforward one (direct rating of importance) is to conduct a survey asking respondents their opinion on the relative importance of different life domains for their lives. Such a study can be conducted in multiple ways. One method is to ask the respondents to rate each life domain with a question like "how important is this life domain (e.g., financial situation) to your life (three choices: not important, important, and very important)" (Campbell et al., 1976). Based on the answers, averages for all respondents or a specific category of respondents can be calculated and these averages can be used to assess the relative importance of life domains. Another method is to ask respondents to rank life domains based on the importance for their quality of life (Campbell et al., 1976). Again, averages per group can be calculated. A problem with these survey methods could be that people might not give honest or insightful answers (Campbell et al., 1976). For example, they might weigh the activity types that they cannot conduct as unimportant (Campbell et al., 1976).

The second method (variance proportion) involves modelling the contribution of activity types to quality of life, using a survey as the basis (Campbell et al., 1976). This survey includes questions about the value of life satisfaction in general and for each life domain. Next the model quantifies what percentage of life satisfaction-variance among the respondents is explained by each life domain's variance (called variance proportion) (Andrews \& Withey, 1974; Campbell et al., 1976; Cummins et al., 2003). The variance proportion is then used to represent the importance of the life domain for life satisfaction. It is possible that the higher variance proportion of one life domain could be due to the fact that that life domain explains a large part of life satisfaction. In this situation, the variance proportion can be used to represent the relative contribution of the life domain to life satisfaction. However, the high variance proportion might also be caused by the life domain's high variance among the people. In this situation, the variance proportion could also be high, even though its contribution to life satisfaction is low. Consequently, it is risky to use this method to assess the contribution of activity types to quality of life.

The third method (regression coefficients) is similar to the second one. It involves the same survey as the second method to get the satisfaction value for life satisfaction and the life domains. Next, a multilinear regression is conducted to model the relation between life satisfaction (dependent variable) and life domain-satisfaction (independent variables) (Campbell et al., 1976). The regression coefficients for each life domain express how much life satisfaction would change if the life domain-satisfaction changes one unit. The higher the regression coefficient value is, the stronger the impact the corresponding life domain has on life satisfaction.

Campbell et al. (1976) applied these three methods to quantify the contribution of life domains to quality of life. The rankings of life domains according to the third method (regression coefficients) and the second method (variance proportion) were quite similar. One exception is that the life domain "non-working activities" is ranked higher by the regression coefficient method than by the variance proportion method. One possible reason for this difference is that the satisfaction with "non-working activities" varies more significantly between individuals than the satisfaction with other life domains. Thus, "non-working activities" play a significant role in creating this variance in life satisfaction, even though the contribution to quality of life is relatively small. The ranking of life domains according to the first method (direct rating of importance) and the third method (regression coefficients) are quite different. For example, "family life" and "marriage," which are ranked as most important (1st and 2nd, respectively) according to regression coefficients, are ranked as almost the least important (10th and 
11 th, respectively) according to the direct rating of importance. Andrews and Withey (1974) and Saxena et al. (2001) adopted the third method, and Cummins et al., (2003) adopted the second and the third method to quantify the relative importance of life domains.

We want to use the relative contribution of life domains to quality of life to generate weighting factors. "Relative contribution to quality life" should reflect quantitatively how much "quality of life" would change if "satisfaction with each life domain" changes a unit. This is exactly what the regression coefficient value means (the result of the third method). The result of a survey (first method) might not reflect people's real perception; variation proportion (result of the second method) is not equal to the regression coefficient value. So, we conclude that of these three methods the third method is to be preferred. We do not claim this to be the only good method, but we utilize this method in our attempt to quantify the relative importance of life domains for quality of life.

A number of studies provide quantitative values. Andrews and Withey (1974) and Campbell et al. (1976) included the most detailed and complete life domains, linking each life domain with the questions used in the survey and explaining clearly which activity types are included in each life domain. However, both studies are rather old, dating from the 1970s in USA. The ranking of the regression coefficient values is comparable in both studies for the life domains studied.

Three studies (Cummins et al., 2003; Saxena, et al., 2001; The World Health Organization Quality of Life Group, 1998) were carried out more recently, and the ranking of most activity-related life domains is comparable with the ranking in the two studies in 1970s, except for "health." However, the life domains included in these studies are either not as detailed or as complete as the two studies from the 1970s. Of these three newer studies, the life domains included in Saxena et al. (2001) are the most detailed, and similar — and thus comparable — to the two 1970s studies. "Health" is ranked first in Saxena et al. (2001) but as relatively unimportant in Andrews and Withey (1974). Besides, "health" is ranked first in World Health Organization Quality of Life Group (1998) and ranked third out of seven life domains in Cummins et al. (2003).

The life domains included in Andrews and Withey (1974) are very detailed and complete, the meaning of each life domain is clear, and the rankings of the life domains are quite comparable with the three studies carried out more recently. We chose, therefore, to mostly adopt the regression coefficient values presented in Andrews and Withey (1974) to represent the relative importance of the life domains for life satisfaction and modify the values with the three newer studies:

1) The life domain "getting new knowledge $\&$ information" is not included in Andrews amd Withey (1974) but is included in the other studies. To obtain a complete set of life domains we also included it in our study. We did so by selecting at least one other study that includes that life domain. We select another life domain with a comparable value with the missing life domain in other studies and is included in both the Andrews and Withey (1974) and other studies. We assume the regression coefficient of the other life domain would also apply to the mission life domain.

2) Note that health is ranked first in Saxena et al. (2001), which is quite different from its ranking in Andrews and Withey (1974). We therefore increased the regression coefficient value for health to be the highest. In Andrews and Withey (1974), the life domain with the highest regression coefficient value is "financial status/ job." We do not know exactly how much higher the value for "health" should be. In Saxena et al. (2001), the importance of "health" and "happiness and enjoyment of life" is similar for the average condition of three central European cities (Tilburg in Netherlands, Paris in France, and Barcelona in Spain). We used the regression coefficient value for "amount of fun" (probably strongly related to "happiness and enjoyment of life") to represent the regression coefficient value of "health," which is 0.15 . The modified regression coefficient value is shown in Table 2. 
Table 2. Life domain's relative contribution to quality of life

\begin{tabular}{|l|l|l|l|l|l|l|}
\hline Life domains & $\begin{array}{l}\text { Financial status } \\
\text { or job }\end{array}$ & $\begin{array}{l}\text { Neighborhood } \\
\text { index }\end{array}$ & Schools & $\begin{array}{l}\text { Consumer } \\
\text { index }\end{array}$ & Health & Friendship \\
\hline $\begin{array}{l}\text { Relative } \\
\text { importance to } \\
\text { quality of life }\end{array}$ & 0.15 & 0.04 & 0.06 & 0.07 & $\mathbf{0 . 1 5}$ & 0.06 \\
\hline $\begin{array}{l}\text { Life domains } \\
\text { Relative } \\
\text { importance to } \\
\text { quality of life }\end{array}$ & Religious faith & Organizations & $\begin{array}{l}\text { Recreation } \\
\text { index }\end{array}$ & $\begin{array}{l}\text { Natural } \\
\text { environment }\end{array}$ & $\begin{array}{l}\text { Getting new knowl- } \\
\text { edge \& information }\end{array}$ \\
\hline
\end{tabular}

Note: For the life domains shown in not-bold type, their relative importance to quality of life is equal to the regression coefficient values in Andrew and Withey (1974). For the two life domains shown with bold type ("health" and "getting new knowledge \& information"), their relative importance to quality of life was modified. We departed from the results from Andrew and Withey (1974), and modified the values based on the three more recent studies using the methods mentioned above. For all the life domains except "getting new knowledge \& information," their exact meaning and the questions used to generate people's satisfaction with these life domains are described in detail in Andrew and Withey (1974). The life domain "getting new knowledge $\&$ information" is not included in Andrew and Withey (1974) but is included in Saxena et al. (2001) and the meaning is described in Saxena et al. (2001). Based on the life domains' description in these two literatures, we built the corresponding relation between activity types and life domains shown in Table 3.

\section{$3 \quad$ Steps to weigh accessibilities over different activity types and its application}

This section describes how the principles presented in Section 2 were applied to develop weighting factors. First, the steps to generate weighting factors will be presented. Then we will examine how the method was applied to Germany to generate weighting factors.

\subsection{Steps to generate weighting factors to combine accessibilities over activity types}

Based on the four principles and the underpinned theories presented in Section 2, we conducted the following procedures to obtain weighting factors for accessibilities of different activity types:

1) Collecting the following information: the human need (the fundamental need or the supplemental need) each activity type satisfies; the relative contribution of each life domain to quality of life (see Table 2); the trip frequency of each activity type; the activity types needed in the emergency situation; and the social values and policy preferences that are related to the importance of the activity type. Note that the latter two are examples in the fourth category of additional principles as presented in Section 2.1.

2) Categorizing activity types into two groups according to the human need they satisfy: the fundamental need or the supplemental need.

3) Categorizing activity types to each life domain and assign each life domain's relative contribution to quality of life (see Table 2) to the corresponding activity type(s). We generated the relative contribution of the life domains to quality of life (see Table 2) based on the results in Andrew and Withey (1974), Cummins et al. (2003), Saxena, et al. (2001) and The World Health Organization Quality of Life Group (1998). Readers can adopt the factors we generated in Table 2, or they can develop the factors themselves by referring to other literature that fits their research area or aims better, or they can even collect their own data, and analyze them using the regression coefficient method (questionnaires; multi-linear regression analysis) to generate regression 
coefficient values to represent the relative contribution of the life domains to quality of life.

4) Calculating weighting factors for each activity type with the next function in the following manner: weighting factor $=$ activity type's relative importance to quality of life $\times$ trip frequency $x$ adjusting factor according to the fourth principle (further modification principle: whether needed in emergency situation, social values and policy preferences). If one activity type appears in more than one life domain, then the highest value that represents the life domain's relative importance to quality of life was chosen to calculate the weighting factor. Note that information on trip frequency and adjusting factors is collected in step 1.

5) Standardizing the weighting factors resulted in step 4 for each of the two activity groups, which are classified according to the human needs the activities satisfy. In this way, the sum of weighting factors for each group equals 1 , which makes the aggregated accessibility value comparable with the accessibility value for each activity type. The standardized values form the weighting factor sets for the two activity groups.

\subsection{Application example: Generating weighting factors in Germany}

We applied the method to Germany, to illustrate how this method can be applied. The aim is to derive a quantitative set of weighting factors per activity category. This set can then be used to calculate aggregated accessibility for several activity types, although these calculations are beyond the scope of this paper.

MiD (Mobilität in Deutschland/ Mobility in Germany, data available in http://www.mobilitaet-indeutschland.de) is the German national household travel survey focusing on households' and individuals' travel behavior. The most recent available data when we did the research was collected in 2008 . We used this dataset to obtain the weighting factors.

In the MiD dataset, the following trip types are included: "work," "business trip," "education," "shopping," "private chore," "accompany others," "leisure," "back to home," and "back to the previous intermediate location in case of a trip chain." The categories "shopping," "private chore" and "leisure" are further disaggregated into the following more detailed trip types: "everyday shopping (e.g., food)," "extra shopping (e.g., clothes, furniture)," "shopping for fun," "go for services (e.g., hairdressers)," "other shopping activities" (all disaggregations of shopping), "see doctor," "go to authorities, banks, post offices, ATMs," "private chore activities for others," "other private chore activities" (all disaggretations of private chore), "visit/visited by friends," "visit cultural facilities (e.g., cinemas, theatres, museums)," "visit events (e.g., football games, markets)," "go for sport," "training (e.g., language courses, night courses)," "eating out (e.g., restaurants, etc.)," "garden house and weekend house," "holiday," "outings (more than 1 day)," "walking," "walk the dog," "jogging," "go to church and graveyard," "volunteering, club, political activities," "work in free time for financial reasons," "hobby," "youth center," "playground, play on the streets," "other leisure activities" (all disaggregations of leisure).

Our paper includes all these trip types except "accompany others," "back to home," "back to the previous intermediate location in case of a trip chain," "other shopping activities," "private chore activities for others," "other private chore activities," and "other leisure activities." We exclude "back to home" and "back to the previous intermediate location in case of a trip chain" because they refer to trip types only, not to activities. Note that the related trips to the activities are included. We excluded "accompany others" and "private chore activities for others" because these activities are intended to help others, and it is less obvious that they contribute to the quality of life of the persons that make the related trips. The trip type "other shopping activities," "other leisure activities" and "other private chore activities" are also excluded since we do not know exactly which activities are included in these three trip types. But we can expect that most "other shopping activities" and "other leisure activities," if not all, are covered respectively by the life domain "consumer index" and "recreational index." In our life domain set, the 
private chore activities in the MiD data set correspond to different life domains, e.g., the activity type "see doctor" corresponds to "health" life domain, while "go to authorities, banks, post offices, ATMs" corresponds to "neighborhood index" life domain. Thus, it could be that there are private chore activities covered by the trip type "other private chore activities" in the MiD data set, and that these activities correspond to life domains that are not listed in our life domain index. If in future applications more shopping, leisure or private chore activities were identified, they are covered by the life domain set in our paper, and if trip frequency data are available, their weighting factors can be generated with our method (the five steps shown in Section 3.1).

To conclude: our dataset covers almost all activity types, possibly omitting "other shopping activities," "other leisure activities" and "other private chore activities," which very likely have a very small share in all activities.

Table 3 shows the corresponding relation between activity types and human needs categories, life domains, emerging situations and social values and policy preferences.

First, we will explain the assumptions we made. The activity type "see doctor in hospitals" was the only one labelled as an "emergency situation" (even though not all trips to hospital are necessarily emergency trips). The dataset only provides trip frequencies for "see doctor," which includes seeing doctors in clinics and in hospitals. Since the majority of these trips are trips to clinics, ${ }^{3}$ all the trips to see a doctor were assigned to the activity type "see doctor in clinics." The weighting factor of the activity type "see doctor in hospitals" was assumed to be the same as the weighting factor of the activity type "see doctor in clinics." We only adjusted the so-called "shorter legs shorter trips" activity types because of social values and political preferences, by assigning a correction factor of 2 to these trips. These activity types are "education in kindergartens" and "education in primary schools." This political preference has been accepted by a number of German states, for example Nord-Rhein-Westfalen (Admin, 2017).

As shown in the table, the share of all trips (presented as a percentage) was calculated for each activity group, and activity types were categorized according to human needs (the fundamental need and the supplemental need) they satisfy. In this way, the trip frequency was standardized for each activity group. This makes it possible to compare the standardized trip share with the standardized weighting factors. Weighting factors do not differ depending on the question of whether the trip shares are calculated per human needs category or for all activity types together. This is because the weighting factors depend on the relative value of the trip share, not on the absolute value. The standardized weighting factors are also displayed in the right column in Table 3.

Comparing the value sets "trip share" and "standardized weighting factor" for each activity group, the two value sets are quite different for fundamental human needs, but quite similar for supplemental human needs. Among activities to satisfy fundamental needs, weighting factors are significantly higher for the activity types related to "financial status/ job" and "health" life domains. This is because "financial status/ job" and "health" life domains have significantly higher regression coefficient values. Among activities to satisfy supplemental needs, weighting factors are slightly higher for the activity types related to the life domains of "recreation index" and "getting new knowledge and information." Of course, multiplying the factors of "emergency" and "social values and political preferences" also influences the final weighting factors.

\footnotetext{
${ }^{3}$ This argument is based on the data set of the Transport Model in Aachen, which was prepared by the Institute of Urban and Transport Planning, RWTH Aachen University, Germany, and is owned by RWTH Aachen University, Germany.
} 
Table 3. Relative importance, trip shares and weighting factor per activity type

\begin{tabular}{|c|c|c|c|c|c|c|}
\hline \multirow{2}{*}{$\begin{array}{l}\text { Human } \\
\text { Needs }\end{array}$} & \multicolumn{2}{|l|}{ Life Domains } & \multicolumn{2}{|l|}{ Activity types } & \multirow{2}{*}{$\begin{array}{l}\text { Further modification } \\
\text { factors: emergency, } \\
\text { social values and policy } \\
\text { preferences }\end{array}$} & \multirow{2}{*}{$\begin{array}{l}\text { Standardized } \\
\text { Weighting Factors }\end{array}$} \\
\hline & Life domains & $\begin{array}{c}\text { Relative } \\
\text { importance to } \\
\text { quality of life1 }\end{array}$ & Activity types & $\begin{array}{l}\text { Share } \\
\text { in trips } \\
(\%)^{1}\end{array}$ & & \\
\hline \multirow{14}{*}{$\begin{array}{l}\text { The } \\
\text { Fundamental } \\
\text { Need }\end{array}$} & \multirow{5}{*}{$\begin{array}{l}\text { Financial status } \\
\text { or job }\end{array}$} & \multirow[t]{5}{*}{0.15} & Work & 25.5 & n.a. ${ }^{2}$ & 0.317 \\
\hline & & & Business trip & 18.4 & n.a. & 0.228 \\
\hline & & & $\begin{array}{l}\text { Education during } \\
\text { work }\end{array}$ & 1.1 & n.a. & 0.014 \\
\hline & & & $\begin{array}{l}\text { Education in } \\
\text { University }\end{array}$ & 0.9 & n.a. & 0.012 \\
\hline & & & Work in free time & 0.2 & n.a. & 0.003 \\
\hline & $\begin{array}{l}\text { Neighborhood } \\
\text { index }\end{array}$ & 0.04 & $\begin{array}{l}\text { Go to authority, } \\
\text { bank, post office, } \\
\text { ATM; }\end{array}$ & 3.3 & n.a. & 0.011 \\
\hline & \multirow[t]{3}{*}{ Schools } & \multirow[t]{3}{*}{0.06} & $\begin{array}{l}\text { Education in } \\
\text { kindergartens }\end{array}$ & 1.5 & $\begin{array}{l}\text { Social values and policy } \\
\text { preferences Adjustment } \\
\text { factor: } 2\end{array}$ & 0.015 \\
\hline & & & $\begin{array}{l}\text { Education in } \\
\text { primary schools }\end{array}$ & 2.5 & $\begin{array}{l}\text { Social values and policy } \\
\text { preferences Adjustment } \\
\text { factor: } 2\end{array}$ & 0.025 \\
\hline & & & $\begin{array}{l}\text { Education in } \\
\text { middle schools }\end{array}$ & 5.8 & n.a. & 0.029 \\
\hline & \multirow[t]{3}{*}{$\begin{array}{l}\text { Consumer } \\
\text { index }\end{array}$} & \multirow[t]{3}{*}{0.07} & $\begin{array}{l}\text { Everyday } \\
\text { shopping (e.g., } \\
\text { food) }\end{array}$ & 28.1 & n.a. & 0.163 \\
\hline & & & $\begin{array}{l}\text { Extra shopping } \\
\text { (e.g., clothes, } \\
\text { furniture) }\end{array}$ & 4.7 & n.a. & 0.027 \\
\hline & & & $\begin{array}{l}\text { Go for services } \\
\text { (e.g., hair dresser) }\end{array}$ & 2.3 & n.a. & 0.013 \\
\hline & \multirow[t]{2}{*}{ Health } & \multirow[t]{2}{*}{0.15} & $\begin{array}{l}\text { See doctor in } \\
\text { clinics }\end{array}$ & 5.8 & n.a. & 0.072 \\
\hline & & & $\begin{array}{l}\text { See doctor in } \\
\text { hospitals }\end{array}$ & n.a. & Emergency & 0.072 \\
\hline \multirow{11}{*}{$\begin{array}{l}\text { The } \\
\text { Supplemental } \\
\text { Need }\end{array}$} & Friendship & 0.06 & $\begin{array}{l}\text { Visit/visited by } \\
\text { friends }\end{array}$ & 27.6 & n.a. & 0.254 \\
\hline & & & Eating out & n.a. & n.a. & n.a. \\
\hline & Religious faith & 0.03 & $\begin{array}{l}\text { Go to church and } \\
\text { graveyard }\end{array}$ & 5.0 & n.a. & 0.023 \\
\hline & Organizations & 0.04 & Youth center & n.a. & n.a. & n.a. \\
\hline & \multirow{7}{*}{$\begin{array}{l}\text { Recreation } \\
\text { index }\end{array}$} & \multirow[t]{7}{*}{0.07} & Shopping for fun & 5.4 & n.a. & 0.058 \\
\hline & & & Eating out & 7.8 & n.a. & 0.083 \\
\hline & & & $\begin{array}{l}\text { Visit cultural f } \\
\text { acilities }\end{array}$ & 2.4 & n.a. & 0.025 \\
\hline & & & Visit event & 3.4 & n.a. & 0.036 \\
\hline & & & Go to sport & 10.7 & n.a. & 0.115 \\
\hline & & & $\begin{array}{l}\text { Garden house and } \\
\text { weekend house }\end{array}$ & 2.2 & n.a. & 0.023 \\
\hline & & & $\begin{array}{l}\text { Outings (more } \\
\text { than } 1 \text { day) }\end{array}$ & 1.5 & n.a. & 0.016 \\
\hline
\end{tabular}




\begin{tabular}{|c|c|c|c|c|c|}
\hline & & Holiday & 0.5 & n.a. & 0.006 \\
\hline & & Walking & 15.8 & n.a. & 0.169 \\
\hline & & Walk the dog & 8.6 & n.a. & 0.092 \\
\hline & & Jogging & 2.1 & n.a. & 0.022 \\
\hline & & $\begin{array}{l}\text { Volunteering, } \\
\text { club, political } \\
\text { activities }\end{array}$ & 2.1 & n.a. & 0.023 \\
\hline & & Hobby & 2.8 & n.a. & 0.030 \\
\hline & & Youth center & 0.2 & n.a. & 0.002 \\
\hline & & $\begin{array}{l}\text { Playground, play } \\
\text { on the streets }\end{array}$ & 1.3 & n.a. & 0.014 \\
\hline $\begin{array}{l}\text { Natural } \\
\text { environment }\end{array}$ & 0.05 & $\begin{array}{l}\text { Garden house and } \\
\text { weekend house }\end{array}$ & n.a. & n.a. & n.a. \\
\hline $\begin{array}{l}\text { Getting new } \\
\text { knowledge \& } \\
\text { information }\end{array}$ & 0.07 & Training & 0.7 & n.a. & 0.008 \\
\hline
\end{tabular}

${ }_{1}$ "Trip share" is calculated with MiD data (http://www.mobilitaet-in-deutschland.de)

2 "Relative importance to quality of life" is represented by the regression coefficient (Andrews \& Withey, 1974)

The following steps were used to generate aggregated accessibility using the weighting factors:

1) Quantify accessibility using accessibility measures for each activity type and each transport mode. There are many measures to quantify accessibility, the one used most often is the gravity measure " $A_{i m}=\sum_{j}\left(S_{j} \times f\left(t_{i j m}\right)\right)$ " (Pirie, 1979; Shen, 1998), where $A_{i m}$ is the accessibility using transport mode $m$ of zone $i$; $S$ is the attractiveness of activity facilities (e.g., floor space of retail shops) in zone $\mathrm{j} ; \mathrm{t}_{\mathrm{ijm}}$ is the travel resistance between zone $\mathrm{i}$ and zone $\mathrm{j}$ (e.g., travel distance, travel time, or monetary travel cost) using transport mode $\mathrm{m} ; \mathrm{f}\left(\mathrm{t}_{\mathrm{ij \textrm {m }}}\right)$ is the impedance function of transport mode $m$ which decreases with increasing travel resistance. The attractiveness of different activity types $\left(S_{j}\right)$ might be quantified in a different way, e.g., the attractiveness of "shopping" might be quantified by the sum of floor space of the shopping facilities in the analysis zones, the attractiveness of "work" might be quantified by the total number of employees in the analysis zone, the attractiveness of "visiting friends" might be represented by the total population number in the analysis zone, and the attractiveness of "seeing doctors" might be represented by the total number of doctors in the analysis zone, etc. The data of attractiveness is available in the local transport model, open street map (www.openstreetmap.org) or HERE GIS Map (www.here. com). Alternatively the number of facilities can be used to represent attractiveness, or - in case of poor data availability — even using only "whether there is facilities for this activity or not" to represent attractiveness (if yes, the attractiveness-value is 1 , if no, the attractiveness-value is 0 ). Since the unit of the activity-attractiveness differs among activity types, the unit and value-range of accessibility vary among activity types. Accessibilities of different activity types are not comparable. Hence, prior to combining the accessibilities of different activity types, the accessibility of each activity type should be standardized.

2) Combine accessibilities of different activity types using the weighting factors for each transport mode.

3) The result is the aggregated accessibility for each transport mode and each activity group.

We applied this method for the Aachen Region in Germany to calculate aggregated accessibility. As an illustration Figure 3 shows the results for activities satisfying fundamental needs. It is beyond the aim of this paper to present and discuss the results in detail, we only aim to illustrate that it is relatively easy to apply the method in a real-world case, based on data sets that are already available. 

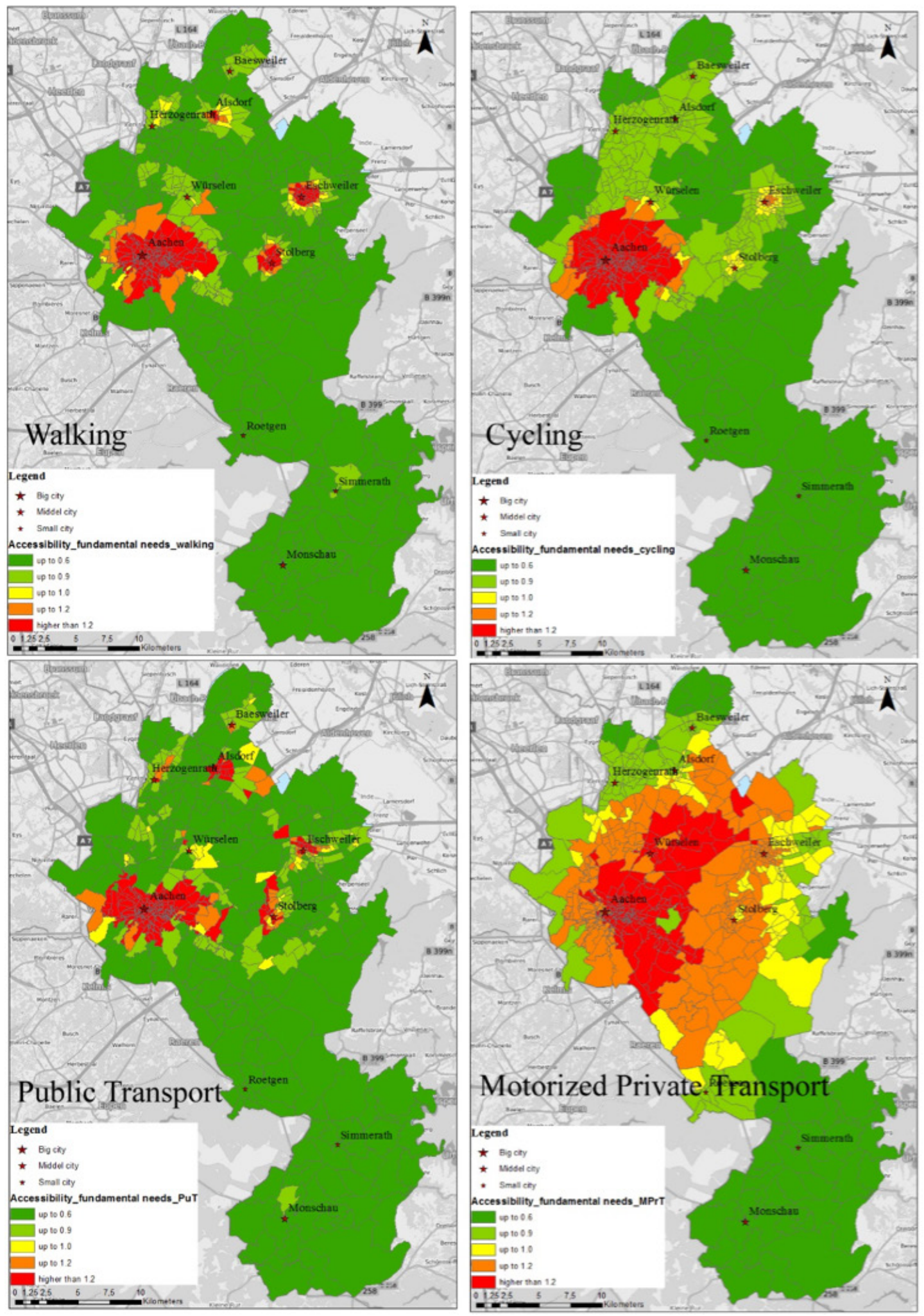

Figure 3. Aggregated accessibility of activities to satisfy fundamental needs by each mode ${ }^{4}$

${ }^{4}$ In order to quantify accessibility, we used the data of travel time between traffic zones from the Transport Model in Aachen, which is owned by RWTH Aachen University, Germany. 


\section{$4 \quad$ Discussion and outlook}

Aggregated accessibility including access to multiple activity types is important for policy making. If policy makers want to assess the accessibility implications of transport or land-use policies, or of external factors (for example population decline), aggregated accessibility is an efficient way of expressing these implications. A trade-off can then be made of accessibility and other pros and cons of such policies. However, literature on how to aggregate is lacking. We found only one paper that proposes using trip frequency to weigh accessibility for different activity types.

In this exploratory paper we proposed weighing access to different activity types based on the activity types' relative importance to quality of life. Since all activities in daily life are (potentially) important for quality of life, we combined the accessibilities of all well-defined activities in the German national household travel survey "MID" in our method. If researchers want to include only specific activities, they can still use our method combining these activities' accessibilities.

As explained above, our life domain set covers all daily activity types in Germany, except some not defined ("other") shopping activities, leisure activities and private chore activities. It is possible that in other regions or countries, there are other activity types not covered by our life domain set. We expect their share to be very low, because we cover a very wide set of activities. In that case, researchers will need to obtain the information on the extra life domains' relative importance to quality of life.

We argued that trip frequency alone cannot adequately represent this relative importance. We proposed a method to determine relative importance based on four principles: the human needs that activity types satisfy; the corresponding activity types' relative contributions to quality of life; trip frequency; further modification corrected by other principles, e.g., whether the activity types are needed in emergency situations, social values and policy preferences. This method was applied to a specific area in Germany. The weighting factors are quite similar to trip shares. Trip shares were combined with activity types' contribution to quality of life; whether activity types relate to emergency situations; and whether activity types reflect specific social values or policy preferences.

Our method is a first attempt to calculate aggregated accessibility. Although we underpinned our method theoretically, we realize it is open for further improvements and modifications. We see several opportunities for future research. First, the proposed method can be verified based on interviews with planners, policy makers, social psychologists and other experts and actors. Next the weighting factors can be based on a wider range and more recent preferences of citizens, obtained by conducting questionnaires to get the people's perception on the value of life satisfaction in general and for each life domain. A multi-linear regression analysis can be made to model the relation between life satisfaction (dependent variable) and life domain-satisfaction (independent variables), and the regression coefficient value can be used to represent the relative contribution of different life domains to quality of life.

Next, our method needs data to describe activities' attractiveness in each analysis zone, e.g., the number of teachers in primary school for "education at primary schools." These data are available in the local transport model, open street map (www.openstreetmap.org) or HERE GIS Map (www.here.com).

In addition, we see added value in combining aggregate accessibility over different transport modes. This could be relevant from a quality of life perspective for multiple reasons. First it is possible that the availability of multiple modes increases the flexibility of reaching destinations, which people might value positively. Secondly, and related, people might value having options to reach the destinations available, even if they do not use them, which is expressed in the concept of the option value (Geurs, Haaijer, \& van Wee, 2006). So, having the option available to reach the destination by a mode not yet used might contribute to people's quality of life. Thirdly, people's levels of wellbeing are mode specific (De Vos, Schwanen, van Acker, \& Witlox, 2012), active modes being valued more highly than car and public transport. So people might feel better if on days with nice weather they are able to walk or cycle to destinations. 
Next, in line with Saxena et al. (2001) we argue that the relative importance of activity types for quality of life can be country and culture specific. Therefore, we recommend empirical research focusing on the specific geographical area. Besides, accessibility to activities is relevant to broader social, economic and environmental goals, so politicians could be included to decide the relative importance of activity types, which would make it easier for them to accept the accessibility analysis result and apply accessibility planning in practice (Straatemeier \& Bertolini, 2008).

Sensitivity analyses can reveal how important assumptions like weighting factors based on the fourth principle are for the final results. It is also possible that there are more options to be included in that fourth category_future research could reveal which.

\section{Acknowledgements}

We thank China Scholarship Council for supporting the first author Lijuan Zheng's doctoral study. And we thank two anonymous reviewers for their useful comments on our draft paper. 


\section{References}

Admin. (2017, October 13). Initiative “Kurze Beine- Kurze Wege." Retrieved from http://www.kurzebeinekurzewege.de/

Alderfer, C. P. (1969). An empirical test of a new theory of human needs. Organizational Behavior and Human Performance, 4, 142-175.

Andrews, F. M., \& Withey, S. B. (1974). Developing measures of perceived life quality: Results from several national surveys. Social Indicators Research, 1, 1-26.

Bergstad, C. J., Gamble, A., Hagman, O., Polk, M., Gärling, T., Ettema, D., .. \& Olsson, L. E. (2012). Influences of affect associated with routine out-of-home activities on subjective well-being. Applied Research in Quality of Life, 7, 49-62.

Betz, E. L. (1984). Two tests of Maslow's theory of need fulfillment. Journal of Vocational Behavior, 24, 204-220.

Campbell, A., Converse, P. E., \& Rodgers, W. L. (1976). The quality of American life: Perceptions, evaluations, and satisfactions. New York: Russell Sage Foundation. Retrieved from https://books. google.de/books?hl=zh-CN\&lr=\&id=h_QWAwAAQBAJ\&oi=fnd\&pg=PA21\&dq=the+qual ity+of + american+life\&ots=gKIenCQkJC\&sig=aZm2Iup6v48JL4L44HMUCs-YHZA\&redir esc $=\mathrm{y} \# \mathrm{v}=$ onepage $\& \mathrm{q}=$ the quality of american life $\& \mathrm{f}=$ false

Cervero, R., \& Kockelman, K. (1997). Travel demand and the 3Ds: Density, diversity, and design. Transportation Research Part D Transport and Environment, 2(3). doi.org/10.1016/S1361-9209(97)000096

Chapin, F. S. (1968). Activity systems and urban structure: A working schema. Journal of the American Institute of Planners, 34(1), 11-18. doi.org/10.1080/01944366808977214

Costanza, R., Fisher, B., Ali, S., Beer, C., Bond, L., ... Boumans, R. (2007). Quality of life: An approach integrating opportunities, human needs, and subjective well-being. Ecological Economics, 61, 267-276. doi.org/10.1016/j.ecolecon.2006.02.023

Cummins, R. A., Eckersley, R., Pallant, J., van Vugt, J., \& Misajon, R. (2003). Developing a national index of subjective wellbeing: The Australian unity wellbeing index. Social Indicators Research, 64, 159-190.

Curl, A., Nelson, J. D., \& Anable, J. (2011). Does accessibility planning address what matters? A review of current practice and practitioner perspectives. Research in Transportation Business \& Management, 2, 3-11. doi.org/10.1016/j.rtbm.2011.07.001

Dalvi, M. Q., \& Martin, K. M. (1976). The measurement of accessibility: Some preliminary results. Transportation, 5, 17-42.

Department for Transport. (2005). Guidance on accessibility planning in local transport plans. Retrieved from http://www.isemoa.eu/docs/reporting/good_practice/infodocs/Accessibility_Planning_Guidance_Final_030105_amend.pdf

De Vos, J., Schwanen, T., van Acker, V., Witlox, F. (2012). Travel and subjective well-being: A focus on findings, methods and future research needs. Transport Reviews, 33(4), 421-442.

El-geneidy, A. M., \& Levinson, D. M. (2006). Access to destinations: Development of accessibility measures. Retrieved from http://www.cts.umn.edu/Publications/ResearchReports/reportdetail.html?id=1072

Elldér, E. (2014). Residential location and daily travel distances: The influence of trip purpose. Journal of Transport Geography, 34, 121-130.

Ettema, D., Gärling, T., Olsson, L. E., \& Friman, M. (2010). Out-of-home activities, daily travel, and subjective well-being. Transportation Research Part A: Policy and Practice, 44(9), 723-732. doi. org/10.1016/j.tra.2010.07.005 
Fodness, D. (1994). Measuring tourist motivation. Annals of Tourism Research, 21(3), 555-581.

Foth, N., Manaugh, K., \& El-Geneidy, A. M. (2013). Towards equitable transit: Examining transit accessibility and social need in Toronto, Canada, 1996-2006. Journal of Transport Geography, 29, 1-10.

Fox, M. (1995). Transport planning and the human activity approach. Journal of Transport Geography, $3(2), 105-116$.

Geurs, K., Haaijer, R., \& van Wee, B. (2006). Option value of public transport: Methodology for measurement and case study for regional rail links in the Netherlands. Transport Reviews, 26(5), 613-643.

Geurs, K. T., \& Ritsema van Eck, J. (2001). Accessibility measures: Review and applications. Evaluation of accessibility impacts of land-use transportation scenarios, and related social and economic impact. Retrieved from https://rivm.openrepository.com/rivm/handle/10029/9487

Goossens, C. (2000). Tourism information and pleasure motivation. Annals of Tourism Research, 27(2), $301-321$.

Great Britain Social Exclusion Unit. (2003). Making the connections: Final report on transport and social exclusion. Retrieved from http://www.ilo.org/wcmsp5/groups/public/---ed_emp/---emp_policy/--invest/documents/publication/wcms_asist_8210.pdf

Grengs, J. (2015). Nonwork accessibility as a social equity indicator. International Journal of Sustainable Transportation, 9(1), 1-14. doi.org/10.1080/15568318.2012.719582

Halden, D. (2002). Using accessibility measures to integrate land use and transport policy in Edinburgh and the Lothians. Transport Policy, 9, 313-324.

Karou, S., \& Hull, A. (2014). Accessibility modelling: Predicting the impact of planned transport infrastructure on accessibility patterns in Edinburgh, UK. Journal of Transport Geography, 35, 1-11.

Jones, P. M. (1983). Understanding travel behavior. Brookfield, VT: Gower Publishing.

Litman, T. (2017). Evaluating accessibility for transportation planning measuring people's ability to reach desired goods and activities. Retrieved from http://www.vtpi.org/access.pdf

Lucas, K., Bates, J., Moore, J., \& Carrasco, J. A. (2016). Modelling the relationship between travel behaviors and social disadvantage. Transportation Research Part A: Policy and Practice, 85, 157-173.

Maslow, A. H. (1970). Motivation and personality. New York: Harper \& Row. Retrieved from http://sf-walker.org.uk/pubsebooks/pdfs/Motivation_and_Personality-Maslow.pdf

McFadden, D. (1974). The measurement of urban travel demand. Journal of Public Economics, 3, 303328.

Pirie, G. H. (1979). Measuring accessibility: A review and proposal. Environment and Planning A: Economy and Space, 11(3), 299-312. doi.org/10.1068/a110299

Pyrialakou, V. D., Gkritza, K., \& Fricker, J. D. (2016). Accessibility, mobility, and realized travel behavior: Assessing transport disadvantage from a policy perspective. Journal of Transport Geography, 51, 252-269. doi.org/10.1016/j.jtrangeo.2016.02.001

Rawls, J. (1971). A theory of justice. Boston: Harvard University Press.

Reyes, M., Páez, A., \& Morency, C. (2014). Walking accessibility to urban parks by children: A case study of Montreal. Landscape and Urban Planning, 125, 38-47. doi.org/10.1016/j.landurbplan.2014.02.002

Rubulotta, E., Ignaccolo, M., Inturri, G., \& Rofe, Y. (2013). Accessibility and centrality for sustainable mobility: Regional planning case study. Journal of Urban Planning and Development, 139, 115-132.

Saxena, S., Carlson, D., Billington, R., \& Orley, J. (2001). The WHO quality of life assessment instrument (WHOQOL-Bref): The importance of its items for cross-cultural research. Quality of Life Research, 10,711-721. 
Shen, Q. (1998). Location characteristics of inner-city neighborhood and employment accessibility of low-wage workers. Environment and Planning B: Planning and Design, 25, 345-365.

Straatemeier, T., \& Bertolini, L. (2008). Joint accessibility design framework developed with practitioners to integrate land use and transport planning in the Netherlands. Transportation Research Record, 2077, $1-8$.

The World Health Organization Quality of Life Group. (1998). Development of the World Health Organization WHOQOL-BREF Quality of Life assessment. Psychological Medicine, 28, 551-558.

van Wee, B., \& Geurs, K. (2011). Discussing equity and social exclusion in accessibility evaluations. European Journal of Transport and Infrastructure Research, 11(4), 350-367.

Ventegodt, S., Merrick, J., \& Andersen, N. J. (2003). Quality of life theory III. Maslow revisited. The Scientific World Journal, 3, 1050-1057. doi.org/10.1100/tsw.2003.84

Wachs, M., \& Kumagai, T. G. (1973). Physical accessibility as a social indicator. Socio-Economic Planning Sciences, 7, 437-456. doi.org/10.1016/0038-0121(73)90041-4

Yen, S. T., \& Adamowicz, W. L. (1994). Participation, trip frequency and site choice: A multinomialpoisson hurdle model of recreation demand. Canadian Journal of Agricultural Economics, 42, 65-76.

Zhan, G., Yan, X., Zhu, S., \& Wang, Y. (2016). Using hierarchical tree-based regression model to examine university student travel frequency and mode choice patterns in China. Transport Policy, 45, $55-65$. 